\title{
Procedimiento administrativo y posacuerdo: el principio de participación en la formación de las decisiones administrativas
}

\author{
Recibido: 27 de septiembre del 2018 • Aprobado: 18 de octubre del 2018 \\ https://doi.org/10.22395/ojum.v17n35a8 \\ Diana Carolina Sánchez Zapata* \\ Hernán Darío Vergara Mesa"*
}

\begin{abstract}
RESUMEN
El presente artículo analiza el papel que desempeña el principio de participación desde su función dogmática en el procedimiento para la formación de los actos administrativos propios del Estado social de derecho. Lo anterior, con el fin de reivindicar su relevancia en el contexto social y político del posacuerdo y en general, como elemento dinamizador del derecho administrativo colombiano, en tanto reclama actuaciones administrativas abiertas a espacios de participación efectivos de la sociedad civil, escenario indispensable para avanzar en la consecución de la paz como finalidad estatal.
\end{abstract}

Palabras clave: principio de participación; teoría del acto administrativo; posacuerdo; procedimiento administrativo; Estado social de derecho.

\footnotetext{
Este artículo se desarrolla en el marco de la investigación iniciada en febrero del 2018 titulada "La repercusión del principio de participación en la teoría del acto administrativo: un análisis de su incidencia en el carácter unilateral de los actos administrativos en el marco de los procedimientos administrativos para la expedición de licencias ambientales y de la negociación colectiva de los empleados públicos", adscrita al Grupo de Investigación Derecho y Sociedad, línea de derecho público, sublínea de derecho administrativo de la Facultad de Derecho y Ciencias Políticas, Universidad de Antioquia.

" Investigadora principal. Abogada, Universidad de Antioquia, Medellín, Colombia; especialista en Derecho Administrativo y magíster en Derecho de la misma universidad. Profesora asistente, Facultad de Derecho y Ciencias Políticas de la Universidad de Antioquia, Medellín, Colombia. Correo electrónico: diana.sanchez@udea.edu.co Orcid: https://orcid. org/0000-0002-4992-8833
}

". Coinvestigador. Abogado, Universidad de Antioquia, Medellín, Colombia; especialista en Derecho Administrativo, Universidad de Medellín, Medellín, Colombia; magíster en Derecho, Universidad de Antioquia, Medellín, Colombia; Doctor en Derecho, Universidad de Buenos Aires, Buenos Aires, Argentina. Profesor titular, Facultad de Derecho y Ciencias Políticas de la Universidad de Antioquia, Medellín, Colombia Correo electrónico: hernan.vergara@udea.edu.co Orcid: http://orcid. org/0000-0003-2288-2182 


\section{Administrative Procedure and Post-Agreement: The Principle of Participation in the Formation of Administrative Decisions}

\section{ABSTRACT}

This paper analyzes the role of the principle of participation in its dogmatic function in the procedure for the formation of administrative acts under the social rule of law. This, in order to claim its relevance in the post-agreement's social and political context, and in general, as a dynamic element of Colombian administrative law; it calls for administrative actions open to spaces of civil society's effective participation, an indispensable scenario to advance in the achievement of peace as a state purpose.

Keywords: principle of participation; administrative law theory; post agreement; administrative procedure; social rule of law.

\section{Procedimento administrativo e pós-acordo: o princípio de participação na formação das decisões administrativas}

\section{RESUMO}

O presente artigo analisa o papel que o princípio de participação desempenha a partir de sua função dogmática no procedimento para a formação dos atos administrativos próprios do Estado social de direito. O objetivo é reivindicar sua relevância no contexto social e político do pós-acordo e, em geral, como elemento dinamizador do direito administrativo colombiano, ao mesmo tempo em que reclama atuações administrativas abertas a espaços de participação efetivos da sociedade civil, cenários indispensável para avançar na consecução da paz como finalidade estatal.

Palavras-chave: princípio de participação; teoria do ato administrativo; pós-acordo; procedimento administrativo; Estado social de direito. 


\section{INTRODUCCIÓN}

La teoría del acto administrativo es, quizás, la más tradicional de las teorías que fundamentan el andamiaje del derecho administrativo. Los discursos dogmáticos que se ocupan de la estructura, atributos y efectos de este tipo de actos, aún se abordan desde una concepción decimonónica del Estado y de la administración pública como entes superiores que sostienen relaciones de jerarquía y superioridad jurídica con los ciudadanos.

Sin embargo, el estudio de una teoría del acto y del procedimiento administrativo desde la perspectiva de las transformaciones de la administración pública, del principio de legalidad y de sus finalidades, comporta replantear los cánones convencionales bajo los cuales se ha desarrollado la función administrativa del Estado. Lo anterior, como parte de las exigencias y deberes que se le imponen a las Administraciones a partir de su sujeción a los contenidos dogmáticos y programáticos del Estado social y democrático de derecho.

Tal reconfiguración tiene incidencia en las distintas tareas en las que se materializa la actividad administrativa. Se trata de una administración pública que debe dar respuesta a necesidades sociales con amplios estándares de participación y posibilitar esquemas de gobernanza territorial, obligaciones hoy reforzadas por los compromisos adquiridos con la suscripción del Acuerdo de Paz, que no en vano se formuló bajo el enfoque de "paz territorial".
En este sentido, la consecuente implementación jurídica del Acuerdo de Paz amerita su consideración como un componente adicional del análisis contextual de la función administrativa, en la medida en que el posacuerdo se convierte en un factor dinamizador de la administración, de los procedimientos administrativos y de especiales formas de relacionamiento con los ciudadanos. Este artículo examina precisamente, la incidencia que puede tener dicho Acuerdo en la recomposición de tales relaciones a través de los novedosos esquemas de procedimiento administrativo diseñados para darle viabilidad a los compromisos adquiridos por las partes.

El trabajo, que hace parte de una investigación dogmática de tipo documental, se elaboró mediante el análisis cualitativo y buscó incorporar un componente crítico a la reflexión teórica en torno a los elementos y atributos del acto administrativo, especialmente a la unilateralidad, al indagar por el proceso de inserción y desarrollo de la teoría del acto administrativo en Colombia a partir de su relación con el entorno y la realidad social.

Para la consecución del objetivo propuesto, en un primer apartado se analiza la construcción teórica del acto administrativo en Colombia, vinculado a ciertos acontecimientos históricos, sociales, económicos y políticos en los que se instrumentó como categoría para el cumplimiento de fines precisos definidos para la administración pública y el Estado. En una segunda parte, se presentan las características de la administración pú- 
blica y del procedimiento administrativo en el Estado social de derecho, con el fin de resaltar, en la tercera parte, los retos de esta en el posacuerdo, especialmente de cara a la expedición de los actos administrativos.

El capítulo final estudia, a partir del análisis de dos componentes del Acuerdo de Paz, la incidencia del principio de participación en la formación de los actos administrativos y enfatiza en la necesidad de revisiones teóricas de dicho concepto desde el reconocimiento de la manera en la que se transforman sus bases a partir de la transferencia de los grandes temas del Estado constitucional al derecho administrativo.

\section{LA INSERCIÓN DE LA TEORÍA DEL ACTO ADMINISTRATIVO EN COLOMBIA}

El análisis de la institución del procedimiento administrativo, de sus caracteres en el marco de un Estado social de derecho, y a su vez, el reconocimiento de su lugar como escenario para el diálogo entre la administración y los administrados y para la formación de decisiones administrativas, reclama mayores estándares de legitimidad democrática, a instancias de las circunstancias sociales y políticas que demanda la implementación de un Acuerdo de Paz.

Desde esta perspectiva, resulta pertinente efectuar una revisión del proceso de incorporación y recepción de la teoría del acto administrativo en Colombia, como quiera que por su carácter instrumental para la materialización de las finalidades de la administración pública o como manifestación de la función administrativa del Estado, el acto administrativo y la teoría que le da sustento, han obedecido en diferentes momentos históricos, a necesidades diversas que van más allá de los influjos de la tradición y experiencia continental europea de la que es primigeniamente hereditario el derecho administrativo y sus teorías. Ello, con la idea de reconocer el rol y las finalidades a las que se debe esta institución en un escenario transicional hacia la paz.

Lo anterior significa entonces reconocer, como afirma Ospina (2016), que,

\section{[...] hablar de derecho administra- tivo para la paz no constituye una evidencia, ya que este ha servido históricamente a diferentes fines, no siempre los más altruistas; a distintos regímenes políticos e, incluso se ha puesto en contra de los administrados para defender al poder por el poder. (p. 14.)}

En este sentido, la explicación teórica del acto administrativo y en general del derecho administrativo en el país, desde el punto de vista doctrinal, ha estado predominantemente ligada a la explicación de la formación del derecho administrativo francés. De manera excepcional en Colombia, la doctrina -de la mano de autores como Malagón (2007; 2012); Peña (2006; 2008), y López (2007)-. ha planteado la necesidad de encontrar la identidad jurídica de esta disciplina y de sus teorías. Para ello se han servido de otras áreas del conocimiento como la 
historia; de la revisión de los trasplantes normativos y herramientas del derecho comparado; y en general, de la premisa de que la comprensión del derecho administrativo no se puede hacer de manera descontextualizada ni ajena al reconocimiento de los hechos sociales que le han servido de fundamento.

Si bien el contenido eminentemente histórico es una característica del derecho administrativo, del que se predica un nexo indiscutible con las tradiciones nacionales -en el sentido de ser producto de la historia de cada país-, el desarrollo de la dogmática del derecho administrativo ha puesto su acento en la construcción de un sistema autónomo separado del derecho común, y en el análisis jurisprudencial y legislado de las reglas y principios que evidencien esa pretendida especialidad, pero ha descuidado su necesaria conexión con la realidad local nacional y con los presupuestos políticos y sociales que han precedido a su configuración (Cassese, 2014).

Así las cosas, desde el punto de vista dogmático resulta pertinente diferenciar entre el estudio de la explicación histórica del derecho administrativo como disciplina especial -desde la perspectiva de la consolidación de estos sistemas-, y por otra parte, la adaptación de sus teorías y principios en la tradición jurídica de cada país.

El primer aspecto corresponde a lo que se ha considerado como la adopción de un sistema de sometimiento de la admi- nistración pública a un derecho especial determinado por el reconocimiento de un esquema dual de jurisdicciones, en el sentido en el que lo plantean algunos autores en Colombia, como Santofimio (2007). Esta explicación corresponde con la dilucidación de las circunstancias que dan lugar al nacimiento del derecho administrativo en Francia a partir de las condiciones que se propician con la Revolución Francesa en el siglo XVIII.

El segundo aspecto, esto es, la pregunta por la inserción de la teoría del acto administrativo en Colombia, debe comprender tanto la identificación de los caracteres originarios del derecho administrativo -según su nacimiento en Francia-, como las características específicas de la adopción de sus instituciones y teorías en el contexto de este país.

Para el caso colombiano, Malagón (2007) ha propuesto ejercicios investigativos a través de los cuales presenta lo que denomina una contralectura de los orígenes del derecho administrativo, parte de antecedentes como el estudio de la policía y del derecho colonial español, es decir, del derecho indiano y de los límites que comportaban algún tipo de control a las autoridades de la época, no obstante su precariedad y que obedecían a sustratos ideológicos diferentes a los del Estado de derecho. De este modo, Malagón señala que: "Es preciso empezar por analizar el surgimiento del derecho administrativo francés, para así poder entender que nuestro derecho administrativo es una fusión de antecedentes hispánicos, 
iluminismo francés e intervencionismo anglosajón" (p. 15).

Desde la perspectiva de este autor, la declaración de independencia, y más adelante la creación por Simón Bolívar del Consejo de Estado, no producen de inmediato una ruptura con el régimen colonial anterior, muchas de sus instituciones y sistemas de control perviven y posteriormente se readaptan a los postulados del liberalismo. Cassese lo planteó de manera similar en sus estudios sobre la historia del derecho administrativo al analizar el caso francés: la Revolución francesa no produjo una discontinuidad entre el antiguo y el nuevo régimen, por el contrario lo que habría hecho Napoleón habría sido recuperar y desarrollar las instituciones del antiguo régimen y darle continuidad a todo lo que la monarquía absoluta había inaugurado, es decir, a la centralización y a la ampliación de los atributos e instrumentos del poder gubernativo.

Ahora bien, la recepción del acto administrativo como categoría en Colombia y su posterior fortalecimiento se ha detallado por Peña (2008) en una investigación dedicada a la teoría del acto administrativo, cuyo propósito, más allá de explicar de manera conceptual la definición de esta institución, consistió en aproximarse a la forma en la cual se creó la doctrina de forma paulatina alrededor de esta figura en el país. En este estudio se ubica la aparición inicial del concepto de acto administrativo en Colombia entre 1910 y 1930, de manera paralela a la ubicación de los orígenes del derecho administrativo colombiano moderno, mediante el trasplante lento de instituciones francesas.

Algunos de los hitos históricos y políticos que se relacionan con la utilidad de esta institución y se constituyen en antecedentes de su consolidación como parte del derecho administrativo emergente, están asociados a la violencia partidista de finales del siglo XIX y comienzos del XX que justifican la creación de una jurisdicción contencioso administrativo. El periodo de la Regeneración y la necesidad de las élites conservadoras (lideradas por Núñez y Caro) de asegurar un equilibrio entre libertad y orden demandaban una unificación y centralización político administrativa, para la cual el principio de legalidad y la concepción de una estructura normativa jerarquizada resultaban favorables. Peña explica en los siguientes términos la preeminencia que para ese entonces se otorgaba al principio de legalidad como fundamento del poder público:

\footnotetext{
La concepción roussoniana de soberanía, que para esos años comenzaba a ser fuertemente criticada en Francia parecía exhibir sus mayores esplendores en Colombia, a tal punto que aquella idea de la supremacía del legislador llevó a concluir la preeminencia de la ley sobre la Constitución misma. (p. 39)
}

A partir de 1913 nació el movimiento jurisprudencial en el campo administrativo con fundamento en la Constitución de 1886, la Ley 130 de 1913 y la Ley 4 de 1913. Solo hasta mediados de 1930 comenzaron 
a producirse los primeros textos sobre el tema, diferentes a aquellos centrados en los comentarios al Código. Se consolidó así la idea de poder público y el principio de legalidad, con el propósito de encontrar el orden, la seguridad y la unión por medio del peligroso aumento del poder del Estado, y en particular, del poder ejecutivo (Peña, 2008). No obstante esta consideración, no hubo hasta ese momento un desarrollo teórico o doctrinal del acto administrativo, de sus elementos o de sus mecanismos de control.

Después de este periodo, al acto administrativo y a la afirmación de una teoría sustentadora dentro del derecho administrativo le sucedieron varias etapas en Colombia. Una etapa en la que las bases del derecho administrativo coincidieron con los intentos de modernización, el fin de la hegemonía conservadora y las condiciones políticas y sociales que permitieron el ascenso al poder del partido liberal, que se corresponde con la reforma constitucional de 1936. La fundamentación ideológica de estos procesos de cambio se identifica con los presupuestos del Estado de bienestar y la influencia de teóricos del servicio público como (Duguit, 1975).

López Pumarejo promovió la reforma constitucional de 1936, el primer y más sustancial de los cambios que inauguran este periodo en cuestiones jurídicas. La reforma al Código en 1941 mediante la Ley 167 y los primeros desarrollos doctrinales nacionales en la materia (Tascón, Pareja, Archila, Castro, citados por Peña, 2008) se circunscribían a comentarios de las obras de los principales teóricos franceses de aquel momento, la mayoría expositores de la Escuela del Servicio Público: Duguit, Jéze, Bonnard y Hauriou.

Este es el caso, por ejemplo, de la obra de Tascón denominada Derecho Contencioso Administrativo, que alude a la importancia del carácter unilateral de la Administración haciendo referencia a un informe presentado al Congreso de 1939 en el que se indicaba que las entidades de derecho público actuaban unilateralmente, por lo que resultaba "exótica" la aplicación de normas de procedimiento civil (Tascón, 1942).

Los años posteriores a la reforma al Código de 1941, que se verifica mediante el Decreto 2377 de 1959, coinciden con el tiempo de la violencia partidista, el período dictatorial del general Rojas Pinilla y una de las épocas de desequilibrio institucional más difíciles de la historia del país. Según Peña:
Ello pudo conducir a que un derecho como el administrativo, que precisamente desde el ro- manticismo francés fue creado para la protección del individuo y la limitación del Estado, no pudiera ser desarrollado, y en cambio, se diera bajo esquemas que adquirieron serios rasgos de autoritarismo estatal, (2008, p. 72)

Estas circunstancias, aunadas al declive, también llamado "crisis de la noción de servicio público", comportaron un forta- 
lecimiento de la teoría del poder público en el país y de las prerrogativas públicas como criterio que se comienza a asumir de manera determinante para definir la aplicación del derecho administrativo, suceso que por supuesto tuvo influencia sobre la organización administrativa.

Lo anterior se advierte con la reforma organizativa de 1968, en la teoría del acto administrativo y en el fortalecimiento del estudio de sus atributos como algunos de los elementos técnicos que se debían consolidar al lado de la jurisdicción contencioso administrativa, con el fin de darle una concepción y tratamiento unitarios a las decisiones de la administración en el marco de un esquema que, si bien pretendía dar paso a la descentralización administrativa, fortalecía estructuras centralizadas, jerárquicas y verticales de poder.

Después de la influencia que tuvieron los autores franceses aludidos durante la década de 1930, en las décadas posteriores comenzaron a tener injerencia y acogida en los estudios administrativistas a nivel nacional las obras de otros autores, como los argentinos Diez (1961), y Gordillo (1964), el uruguayo Sayagués Lasso (1965) o el español García Oviedo (1962). A partir de estos estudios y de la expedición del Código Contencioso Administrativo de 1984 se afirmó con propiedad la existencia de una teoría del acto administrativo en Colombia, efectivamente definido a partir de la inclusión de temas como los elementos, clasificación, atributos, extinción y procedimientos para su expedición. Resulta pertinente en todo caso, men- cionar que los desarrollos teóricos de los temas anteriores no necesariamente estuvieron acompañados por su desarrollo positivo. Este, además de ser un rasgo distintivo de la última de las etapas mencionadas - esto es, la que se corresponde con la vigencia del Código de 1984-, es una característica que se evidencia a lo largo de todo el proceso de evolución del derecho administrativo en Colombia. En el caso del acto administrativo, esto se manifiesta en el hecho de que nunca se ha efectuado su definición en el derecho legislado y ha sido más el producto de la doctrina y de su aplicación en la práctica judicial.

El recuento anterior muestra que la construcción teórica del acto administrativo en Colombia ha estado vinculada a ciertos acontecimientos históricos, sociales, económicos y políticos en los que se ha instrumentado como categoría del derecho administrativo para el cumplimiento de fines precisos y definidos para la administración y el Estado. Bajo estos acontecimientos, los elementos autoritarios y el afianzamiento del poder público centralizado cobraron protagonismo y estuvieron además al amparo de la Constitución de 1886. A su vez, reivindica la necesidad de vincular el estudio de estos acontecimientos con la elaboración de una dogmática administrativista propia para Colombia.

Ahora bien, con la Constitución de 1991, la definición de un Estado social y la consecuente reconfiguración de las relaciones entre el Estado y la sociedad civil, 
se plantea un escenario diferente para la comprensión de las manifestaciones de la función administrativa, entre ellas, el acto administrativo, de las finalidades de la administración pública y del procedimiento administrativo, como se verá en el apartado siguiente.

\section{LA ADMINISTRACIÓN PÚBLICA YEL PROCEDIMIENTO ADMINISTRATIVO EN EL ESTADO SOCIAL DE DERECHO}

Antes que norma de comportamiento o de derechos, el Derecho es organización (Garrido, 2005). Alguien tiene que garantizarlos para hacerlos tangibles, para que dejen de ser meramente simbólicos. Históricamente, algunos han planteado que antes que el Estado existía la administración (Montaña, 2010), pues siempre ha sido necesario que alguien se encargue de satisfacer los servicios básicos de la comunidad, los cuales han ido variando paulatinamente, en virtud de las transformaciones del modelo estatal y de su consolidación como organización política (Duguit, 1975).

La administración tiene la particularidad de presentar una continuidad histórica, más allá de la tradición constitucional que revelen los Estados, su ductilidad ha permitido que se adapte a los diferentes patrones y se legitime en ellos, en tanto todos promueven, a su manera, la satisfacción de necesidades sociales (Forsthoff, 1958). Tal ductilidad propone dimensiones organizativas y funcionales diferenciadas en virtud de los mandatos establecidos en cada caso como fines del
Estado, por lo cual su fisonomía y procedimientos cambian sustancialmente, dependiendo de la adscripción a modelos liberales o sociales.

En 1992 la Corte Constitucional de Colombia afirmaba que "el término 'social', ahora agregado a la clásica fórmula del Estado de Derecho, no debe ser entendido como una simple muletilla retórica que proporciona un elegante toque de filantropía a la idea tradicional del derecho y del Estado" (T-406, 1992). Por el contrario, tiene implicaciones sustanciales con respecto a la protección de derechos "novedosos" -los de contenido social, económico y cultural- pero también procedimentales sobre la administración pública, pues reorienta su organización al servicio de los intereses generales, comprendiendo dentro de estos $-y$ no necesariamente en términos de pugna- a tales derechos (Giannini, 1991).

El Estado social que acoge la Constitución es, ante todo, un estado administrador (Parejo, 2000), pues sus mandatos tienen la vocación de hacerse realidad en las comunidades y a favor de los sujetos que son sus destinatarios (Rodríguez de Santiago, 2007). Ese modelo que, mediante distintos documentos normativos -llámense Constituciones, actos con fuerza de ley, tratados internacionales, planes de desarrollo, entre otros- impone obligaciones permanentes o circunstanciales al Estado con diferente alcance, requiere inicialmente una organización que pueda articular y ejecutar todos sus elementos básicos, ante todo mediante normas de 
procedimiento según el ámbito que deba intervenir.

Tales normas de procedimiento son esenciales para encaminar la conducta de los agentes públicos hacia el logro de las finalidades sociales y para preservar las garantías básicas de quienes se hallan en la órbita estatal cuando se despliegan las acciones correspondientes, a pesar de que estas no conlleven efectos sancionatorios. Y es que, en realidad, el Estado social se reconoce más por su contenido prestacional, pero aún ante él, las posibilidades y niveles de participación de los ciudadanos se activan en virtud de la índole de los asuntos que los convocan, bien como afectados, bien como colaboradores, ora como facilitadores de la acción estatal.

Las dimensiones del Estado social formulado en la Carta Política se ensanchan a propósito de ciertos documentos político-administrativos recientemente logrados dentro del Estado colombiano. Concretamente, el Acuerdo de Paz pone a prueba la simbiosis que ese modelo de Estado exige entre los elementos organizativos y procedimentales del denso componente prestacional que nutre dicho Acuerdo, como se examina en los siguientes apartados.

\section{LOS RETOS DE LA ADMINISTRACIÓN PÚBLICA EN EL POSACUERDO Y LA EXPEDICIÓN DE LOS ACTOS ADMINISTRATIVOS}

El fin del conflicto armado, problema estructural del Estado colombiano desde hace décadas, produjo una hoja de ruta en el Acuerdo de Paz con las FARC-EP, que luego se tradujo en una serie de normas contenidas en decretos con fuerza de ley, reglamentos e iniciativas legislativas ${ }^{1}$ que intentan definir las condiciones de satisfacción de derechos en múltiples materias, como las de restitución de tierras y asistencia técnica a los campesinos, por solo mencionar algunas de ellas. Todo esto encierra acciones positivas por parte del Estado, prestacionales en su gran mayoría.

En efecto, los compromisos concretos del acuerdo, desarrollados a partir de los seis puntos que, en su conjunto, conforman lo pactado en La Habana, evidencian un interés por materializar el traslado de las decisiones de la esfera política a la práctica, que en armonía con el enfoque territorial allí propuesto, se orientará hacia acciones concretas en los territo-

Los primeros - decretos con fuerza de ley- fueron expedidos mediante el Procedimiento Legislativo Especial para la Paz "fast track", establecido en el Acto legislativo 01 de 2017; los segundos -reglamentos- constituyen iniciativas legislativas de relevancia en la implementación del Acuerdo de Paz, tales como el Proyecto de ley No. 018 de 2017 Cámara - No. 009/2017 Senado "Por la cual se habilita la adjudicación o el otorgamiento de uso de baldíos en reservas forestales protectoras - productoras y de reserva forestal de la Ley $2^{\text {a }}$ de 1959, sin sustracción y se dictan otras disposiciones"; el Proyecto de ley No. 019 de 2017 Cámara - No. 010 de 2017 Senado "Por la cual se regula el sistema nacional catastral multipropósito"; el Proyecto de ley orgánica No. 020 de 2017 Cámara - No. 011 de 2017 Senado "Por la cual se modifica la ley 152 de 1994"; el Proyecto de ley No. 13 de 2017 Senado - 022 de 2017 Cámara "Por medio de la cual se desarrolla el tratamiento penal diferenciado para pequeños cultivadores y cultivadoras, de acuerdo con las disposiciones del artículo 5 transitorio del Acto Legislativo 01 de 2017 y el numeral 4.1.3.4 del Acuerdo Final para la terminación del conflicto y la construcción de una paz estable y duradera". 
rios, entre todos aquellos instrumentos de tipo programático dispuestos en los compromisos logrados.

De acuerdo con el Informe sobre el estado efectivo de implementación del Acuerdo de Paz publicado por el Instituto Kroc de Estudios Internacionales de Paz (2017), a 31 de agosto del 2017 se habían expedido cuatro actos legislativos, cuatro leyes en virtud del procedimiento legislativo especial para la paz y treinta y seis decretos presidenciales con base en facultades extraordinarias. Estos desarrollos normativos incluyen, entre otros, los siguientes aspectos de la Reforma Rural Integral: electrificación y vivienda rural (Decretos 884 y 890 de 2017), Programas de Desarrollo con Enfoque Territorial (Decreto 893 de 2017), Fondo de Tierras (Decreto 902 de 2017), así como lo relativo al Programa Nacional Integral de Sustitución de Cultivos de Uso Ilícito (Decreto 249 de 2017 y Decreto 896 de 2017), entre otros.

Los anteriores desarrollos normativos, en armonía con el contenido del Acuerdo de Paz, comparten dos elementos sustanciales que suponen retos para la administración pública en el ejercicio de la función administrativa. Por una parte, se trata de disposiciones que buscan materializar el enfoque, y a su vez, la finalidad de alcanzar la denominada "paz territorial". Por otra parte, presuponen el cumplimiento y garantía de altos estándares de participación en la adopción de medidas y decisiones por parte de la Administración.
Tales elementos, desde la teleología del Acuerdo de Paz, son imprescindibles, complementarios y adicionalmente, desde el punto de vista de su contenido y su formulación, constituyen enfoques que profundizan en las premisas del Estado social de derecho y en la forma organizativa adoptada por el Estado colombiano. La relación de estos elementos se enuncia de la siguiente manera en el texto del Acuerdo que, al referirse al primero de ellos, señala que:

\section{[...] supone reconocer y tener en cuenta las necesidades, caracte- rísticas y particularidades eco- nómicas, culturales y sociales de los territorios y las comunidades, garantizando la sostenibilidad socio-ambiental; y procurar im- plementar las diferentes medidas de manera integral y coordinada, con la participación activa de la ciudadanía. La implementación se hará desde las regiones y territorios y con la participación de las autoridades territoriales y los diferentes sectores de la sociedad. (Gobierno Nacional y FARC-EP, 2016, p. 4)}

Estas consideraciones son consecuentes y se constituyen en un correlato del reconocimiento del principio de participación que se instaló a partir de la Constitución de 1991. Desde aquel momento, la idea de participación se planteó como la alternativa para la democratización política y económica de la organización estatal, expresada tanto en la posibilidad de participación en la toma de decisiones de las entidades territoriales desde el reconocimiento de su autonomía (Preám- 
bulo y artículos 1 y 2 de la Constitución Política de 1991, ANC, 1991), como en la revaloración de las relaciones del Estado con la ciudadanía, que se materializó con el desarrollo de la democracia participativa y la incorporación de una serie de mecanismos para hacerla efectiva.

No en vano, la idea de participación se postuló para permear todas las esferas de la actuación de los poderes públicos (Pineda Salazar, 1991) y en específico - para los fines que se propone mostrar este artículo-, para la actuación administrativa, entendida como el escenario de concretización de la Constitución (Schmidt-Assmann, 2003).

De esta manera, es posible afirmar que a partir del Estado social de derecho y ahora con el posacuerdo, las finalidades sociales son la base sobre la cual se ejerce la función administrativa, y que en este contexto, la Administración asume nuevas responsabilidades para su cumplimiento. A su vez, las formas y procedimientos a través de los cuales la Administración actúa como consecuencia de esta cláusula "social", se sujetan a una nueva lectura del principio de legalidad, "entendido como principio de juridicidad consecuencia de la importancia y jerarquía que tienen los derechos fundamentales en el Estado social" (Henao, 2014, p. 150), y de las funciones que cumplen los principios, como el de participación, al irradiar la labor de los operadores jurídicos administrativos.

Las finalidades sociales del Estado se manifiestan mediante la garantía y satisfac- ción de aquellos derechos y servicios que hacen posible la igualdad material. El posacuerdo robustece estas finalidades prestacionales al enfatizar en aspectos como:

i) La provisión de bienes y servicios necesarios para la población rural y el fortalecimiento de la infraestructura territorial (vial, de riego, eléctrica y de conectividad) (Decreto 884 de 2017 y Decreto ley 890 de 2017);

ii) El papel de la economía campesina, familiar y comunitaria, y la disponibilidad y accesibilidad de alimentos para la población urbana (Ministerio de Agricultura y Desarrollo Rural, Resolución 464 de 2017);

iii) La participación de las comunidades, en especial de las rurales y de los grupos étnicos, como un componente relativo a las organizaciones y aspectos culturales, que propende por articular y armonizar instrumentos de planeación con los planes de vida, planes de salvaguarda, etnodesarrollo o sus equivalentes, en el caso de las regiones y territorios que incluyan pueblos, comunidades y grupos étnicos (Decreto 893 de 2017);

iv) La existencia de un ordenamiento socio ambiental sostenible que garantice y promueva el acceso al agua;

v) La regularización de la propiedad, a partir de la creación de un fondo de tierras y de un sistema de subsidio y crédito para que puedan acceder a ella las personas sin tierra o con tierra insuficiente. 
De cualquier modo, los derechos prestacionales se hacen posibles a partir de normas de organización (Alexy, 2008), y muy particularmente de procedimiento administrativo. Solo en estas la efectividad del derecho logra tener concreción pues mediante el procedimiento se determinan el escenario y las circunstancias de su efectividad y se constituyen en condición necesaria, aunque no suficiente, para procurar una decisión administrativa con ese propósito (Blanke, 2011).

El procedimiento administrativo se ha visto tradicionalmente como un instrumento que la administración utiliza para para lograr eficacia y legalidad en su decisión. Su lectura como medio para la salvaguarda de derechos en la actuación administrativa no ha sido común, a pesar de que se la reseña doctrinalmente como uno de sus propósitos (Garrido, 2005). Como el debido proceso, y todo lo que él implica, viene precedido de elementales dosis de participación de los interesados en la estructuración de las decisiones administrativas. Tomarlo en cuenta supone replantear en muchos casos, los esquemas autoritarios con los que aún se manifiesta la administración pública en campos muy diversos de la vida social, aún en aquellos que ameritan modos de intervención diferentes.

Barnes (2011) propuso una lectura del procedimiento administrativo a partir de tres grandes generaciones: i) la tradicional, mediante el cual la administración actúa como una autoridad que debe aplicar una norma, previa verificación de sus supuestos básicos, tal cual lo haría un juez en relación con el caso que se le propone dirimir; ii) la de la administración prestacional que debe proveer bienes y servicios, y que en función de eso asume comportamientos similares a los del legislador; y iii) la más novedoso de todas, la de la gobernanza, en virtud de la cual la administración debe incidir en realidades complejas que le exigen el apoyo de otros actores sociales, tanto públicos como privados, para moldear su actuación y tomar decisiones.

Se podría decir que las reglas sobre procedimiento administrativo que actualmente rigen en Colombia (Congreso de la República, 2011) vislumbran las citadas generaciones y por tanto, se muestran lo suficientemente flexibles para regular diferencialmente los comportamientos administrativos y las posibilidades de participación de los ciudadanos en las actuaciones administrativas. La norma general contenida en el Código de Procedimiento Administrativo y de lo Contencioso Administrativo (CPACA) - Ley 1437 de 2011 - parece admitir estas generaciones cuando consagra la participación como uno de los principios del procedimiento administrativo y prevé la intervención amplia de los ciudadanos, las organizaciones y las comunidades en la deliberación, formulación, ejecución, control y evaluación de la gestión pública (Congreso de la República, 2011, art. 3).

Del mismo modo lo hace cuando establece deberes de información a través de distintos medios, de proyectos específicos de regulación, con el objeto de reci- 
bir sugerencias y opiniones de la comunidad (Congreso de la República, 2011, art. 8). También cuando dispone sobre las distintas formas de ejercicio del derecho de petición y el deber de comunicar las actuaciones administrativas a las personas, determinadas e indeterminadas, que puedan resultar afectadas por la decisión (Congreso de la República, 2011, arts. 37 y 38 ).

Todo parece indicar entonces que el procedimiento administrativo colombiano comprende todas las facetas de la actividad administrativa y no meramente la defensiva a la que siempre se le presta atención (Marín Hernández, 2016). A esto se suma que muchas de estas, por sus particularidades, deben orientarse por procedimientos administrativos especiales, con reglas sobre participación adecuadas para su desarrollo, tal como lo autoriza expresamente la misma normatividad (Congreso de la República, 2011, art. 2).

Ahora bien, las materias que concita el posacuerdo son complejas desde muchos puntos de vista. Estas tienen caracteres y finalidades diversos, pues con ellas se pretendió iniciar una fase de transición que contribuyera a una mayor integración del territorio nacional, a una mayor inclusión social y al fortalecimiento de la democracia, de modo tal que se facilite la tramitación de los conflictos sociales por las vías institucionales y con la plena garantía de quienes participan en la vida política del país (Gobierno Nacional y FARC-EP, 2016).
Resulta singularmente relevante que, a lo largo de su texto, el Acuerdo enfatiza en la necesidad de desarrollar procesos participativos, tanto para la formulación y diseño, como para la implementación de las políticas públicas. Se dispone, por ejemplo, la participación como uno de los principios básicos de la Reforma Rural Integral (RRI) (Gobierno Nacional y FARC-EP, 2016) y, en particular, como uno de los presupuestos de los Programas de Desarrollo con Enfoque Territorial (PDET) (Gobierno Nacional y FARC-EP, 2016).

De la misma manera, se erige como eje conductor de la participación política - capítulo medular del Acuerdo- la consideración de que la construcción de la paz es un asunto de la sociedad en su conjunto, por tanto de la participación sin distinción de todas las personas, para que se incida efectivamente en los asuntos de interés público (Gobierno Nacional y FARC-EP, 2016). Por eso y entre otras cosas, el Acuerdo establece medidas concretas que permitan fortalecer la participación de los ciudadanos y las comunidades en uno de los aspectos centrales del desenvolvimiento de la administración pública, como es la conformación y las funciones de los Comités Territoriales de Planeación, mediante los cuales se elabora, discute, audita, ejecuta y evalúan los procesos de planeación y presupuestación que dirigen la acción del Estado (Gobierno Nacional y FARC-EP, 2016).

Incluso, un punto que contiene rasgos propios de los procedimientos de primera 
generación -en tanto buscan estructurar todo un programa de reparación integral a favor de las víctimas del conflicto armado, que supone distintas modalidades de reparación, entre ellas la económica-, prevé de modo novedoso la participación activa de las víctimas y de sus organizaciones en la definición de las prioridades para su implementación, seguimiento y veeduría.

En fin, las menciones a la participación de ciudadanos, comunidades, organizaciones sociales y poblaciones específicas por razón de su vulnerabilidad social y económica, es una constante en todo el Acuerdo de Paz. Esto permite decir que la participación es un principio transversal del Acuerdo y una regla de conducta para la administración pública en toda su implementación.

Ningún documento con relevancia jurídica para el cumplimiento de la función administrativa del Estado colombiano había mostrado, como este, una preocupación tan pronunciada por la participación ciudadana en temas que se anteriormente siempre han sido interpretadas como solo del resorte de la Administración. Y no es para menos, la guerra endémica que ha sobrellevado el país tiene entre sus múltiples causas la exclusión social y el déficit de democracia participativa, los cual ha favorecido a la percepción general de la administración pública como un farragoso conjunto de órganos distantes y autoritarios, con respecto a los cuales solo están las alternativas del padecimiento o la resistencia.

\section{EL PRINCIPIO DE PARTICIPACIÓN EN LA FORMACIÓN DE LOS ACTOS ADMINISTRATIVOS: HACIA UNA REVISIÓN DE LA TEORÍA DEL ACTO EN COLOMBIA}

Los alcances del Estado social mencionados en acápites precedentes, se ven acompañados por un mandato que se constituye a su vez en pilar estructural del Estado, y sin el cual no se puede leer su significado de forma integral: el principio de participación. Este principio cumple, en relación con la tipología de Estado descrita, una función axial de control y a su vez de fundamentación del poder político, en la medida en que la idea de "facilitar la participación de todos en las decisiones que los afectan y en la vida económica, política, administrativa y cultural de la Nación" (Constitución Política de Colombia, 1991, art. 2) se constituye como un fin superior del Estado.

De igual forma, en la línea de las finalidades sociales de carácter prestacional mencionadas, resulta pertinente enfatizar en algunas tipologías de decisiones y actividades de la administración pública, que, como consecuencia de los desarrollos normativos del posacuerdo, reflejan al menos tres características que permitirían reconsiderar aspectos esenciales de la teoría del acto administrativo en Colombia.

En primer lugar, dan cuenta de la complejidad de las obligaciones a cargo de las autoridades, en virtud de formas particulares de expedición de sus decisiones que no se siguen bajo los cánones 
convencionales de formación de las decisiones administrativas. En segundo lugar, se trata de procedimientos de formación de las decisiones en las que la participación ciudadana resulta ser imperativa. Y en tercer lugar, demuestran las transformaciones en la vinculación a la legalidad, en las que, si bien esta permanece como un presupuesto de la actuación administrativa, se reconduce hacia la sujeción a contenidos de carácter principalmente programático. A continuación se analizan algunos ejemplos que permiten evidenciar estas características.

\subsection{Decisiones administrativas en el marco de los pro- cedimientos para la elaboración de los Programas de Desarrollo con Enfoque Territorial (PDET)}

La primera tipología de decisiones con las que se busca ejemplificar estas características, se puede analizar a partir del contenido del Decreto 893 de 2017, por el cual se crean los Programas de Desarrollo con Enfoque Territorial (PDET). Este Decreto dispone la creación de los PDET como el instrumento de planificación y gestión que permitirá implementar los planes sectoriales, programas de la Reforma Rural Integral y medidas pertinentes establecidas en el Acuerdo Final.

Resulta particular que, tratándose de un instrumento de gestión y de planificación, el Decreto no se refiere a su expedición o adopción en términos de su proceso de elaboración, sino en cambio, indica que serán formulados por una vez, con una vigencia de diez años y "serán coordinados por la Agencia de Renovación del Territorio -ART- en ejercicio de las funciones que le son propias [...]" (art. 1). Asimismo, la ART "dirigirá la construcción participativa y la respectiva revisión y seguimiento de los PATR de los PDET, y coordinará la estructuración y ejecución de los proyectos de dichos planes [...]" (art. 7) (subrayado fuera del texto original).

El sentido de la función de coordinación y no así de adopción o expedición, da cuenta de la primera y segunda características anteriormente señaladas. Es decir, se trata de la formulación de un instrumento de carácter complejo a través del cual se pretende cumplir con la finalidad central del Acuerdo de Paz, aquel de "hacer del campo colombiano un escenario de reconciliación" (art. 2), propósito que solo se puede alcanzar en virtud de la garantía de unas condiciones mínimas materiales de existencia para la población de las zonas priorizadas por el Decreto.

Es un instrumento de formación complejo porque su elaboración requiere de la concurrencia y coordinación, no solo de distintas autoridades administrativas que se señalan en el Decreto (entidades territoriales, Gobierno Nacional), sino de diversos instrumentos que se deben armonizar entre sí, según lo establecido por el artículo $6^{2}$. Se trata de una herramienta que contemplará a su vez multiplicidad

\footnotetext{
Según un inventario que hizo la ART al respecto, a marzo de 2018, se trata de la articulación con al menos 42 instrumentos de planeación, entre los que se citan: Plan de Manejo y Ordenamiento de Cuencas (Pomca), Planes de Ordenamiento Social de la Propiedad Rural, planes de ordenamiento territorial, planes de desarrollo, vida, salvaguarda, adaptación al cambio climático, entre otros.
} 
de acciones y decisiones a cargo de la administración o administraciones públicas que se expresarán en programas, proyectos y obras.

Aunque en sí mismos son un instrumento, los PDET requieren ser desarrollados a través de los Planes de Acción para la Transformación Regional (PATR) (art. 4) y además, su diseño comporta un entramado proceso de participación que supone, de manera ineludible, una construcción a través de un esquema participativo desde las veredas de las zonas priorizadas, con un componente y enfoque de género, además de étnico en el caso de comunidades indígenas y afrodescendientes. Este esquema hace vinculante la incorporación en estos planes de las visiones de la comunidad sobre sus territorios, sus necesidades diferenciadas de transformación y mecanismos de control social que incluyan herramientas de difusión y acceso a la información.

En cuanto a la tercera característica, esto es, la vinculación a la legalidad, estos planes prevén un modelo de sujeción que pasa por la articulación de competencias administrativas a través de la aplicación de los principios de coordinación, concurrencia y subsidiariedad, así como por la limitación de los alcances de los instrumentos a lo dispuesto por las normas orgánicas de planeación (artículos 6 y 7 , parágrafo 1), por el sometimiento al marco de la sostenibilidad fiscal (artículo 9) y el respeto de los gobiernos y autoridades propias de las comunidades étnicas (artículo 13).

\subsection{Decisiones administrativas en el marco de los procedimientos para la implementación de la Reforma Rural Integral (RRI)}

Otra tipología de decisiones administrativas que se puede analizar bajo la perspectiva de las características aludidas es la que deriva de lo dispuesto por el Decreto 902 de 2017 "Por el cual se adoptan medidas para facilitar la implementación de la Reforma Rural Integral contemplada en el Acuerdo Final en materia de tierras, específicamente el procedimiento para el acceso y formalización y el Fondo de Tierras". Desde el punto de vista de la formación y expedición de decisiones administrativas, el Decreto hace alusión a varias tipologías.

En primer lugar, hace referencia al acto administrativo que decide el ingreso o rechazo al Registro de Sujetos de Ordenamiento (RESO) (artículo 15). El RESO es una herramienta de información para identificar a los beneficiarios del Fondo de Tierras para la RRI. Se define como un instrumento de planeación y de ejecución gradual de la política pública, bajo el principio de reserva de lo posible, a fin de que el acceso y la formalización de tierras se adelanten de manera progresiva. El acto administrativo que decide la inclusión en el RESO resulta ser muy importante para el logro de las finalidades de la RRI como quiera que, de la inscripción en él, depende la posibilidad de participar en los procedimientos de adjudicación en calidad de sujetos de acceso y formalización. 
Con respecto al acto que decide la inscripción en el RESO, resulta importante advertir que se encuentra precedido por el cumplimiento de una serie de criterios establecidos en el artículo 14 y a un sistema de calificación, en virtud del cual se asigna una puntuación para acceder al RESO. No obstante, su importancia, contra este tipo de actos solo procede el recurso de reposición ante la ANT.

La segunda tipología de actos administrativos que es posible identificar en el Decreto en cuestión, corresponde a los actos administrativos que declaren la titulación y saneamiento de predios y que formalicen la propiedad de los poseedores (artículo 32). Estos actos se expiden luego de cumplir las fases del Procedimiento Único (PU) (artículo 36), el cual se encuentra enunciado en el Título VI artículos 40 y subsiguientes, sobre Implementación del Ordenamiento Social de la Propiedad Rural.

A través del PU se tramitan también asuntos como la asignación de subsidios y créditos a los que alude el Decreto, formalización de predios privados, clarificación de la propiedad, deslinde y recuperación de baldíos, extinción de dominio, entre otros, conforme lo dispone el artículo 58. Con respecto al PU, cabe señalar por un lado, que depende del RESO y del acto administrativo de calificación como sujeto de ordenamiento social y, por el otro, que está condicionado a otro procedimiento que hace referencia a la implementación de los Planes de Ordenamiento Social de la Propiedad Rural (POSPR).
Se advierte entonces una interrelación de procedimientos, en los que la participación aparece con elocuencia y nitidez en los POSPR. En efecto, se resalta en varias oportunidades que se deben formular participativamente, de acuerdo con los criterios establecidos en el artículo 44, que insisten en la participación, tanto para la formulación como para la implementación y mantenimiento de los POSPR. Esta participación comporta la intervención y colaboración efectiva de toda la comunidad y de las autoridades locales, con el fin de responder a las necesidades sobre el territorio y garantizar la transparencia y eficacia de los procesos de intervención.

La participación en estos planes se relaciona con otros criterios que hacen alusión al enfoque territorial y diferencial. El primero alude a la necesidad de incorporar en ellos las especificidades de los territorios y el segundo, al deber de reconocimiento de las poblaciones con características particulares debido a su edad, sexo, etnia, orientación sexual, discapacidad y apunta especialmente, a la priorización de las intervenciones centradas en las mujeres campesinas.

Con respecto al contenido mínimo de estos planes, en el numeral 5 del artículo 45 se determina la necesidad de incluir mecanismos participativos de identificación de potenciales beneficiarios y sujetos de programas de acceso y formalización de tierras, conforme a las reglas del RESO. A pesar de señalar el carácter activo de estos ejercicios participativos, se advierte 
que "en ningún caso limitará la facultad y competencias legales para adoptar decisiones por parte de la ANT y avanzar en los POSPR".

La disposición comentada señala además, que queda a cargo de la ANT la determinación de las formas de participación más idóneas, al igual que el deber de habilitar la intervención de los distintos actores e instancias de participación presentes en el territorio, entre otros, de organizaciones comunitarias, asociaciones de productores, gremios, juntas de acción comunal, instancias de participación de las Zonas de Reserva Campesina de ser el caso, de autoridades, comunidades y organizaciones de los territorios étnicos, en todos los niveles.

De los aspectos hasta aquí descritos, se advierte que en el Decreto 902 de 2017 es posible reconocer también un diseño complejo en el que se entrecruzan y relacionan al menos tres tipos de procedimientos para la formación de diferentes decisiones administrativas: 1) el que da lugar al reconocimiento como sujeto de ordenamiento y a la inscripción al RESO; 2) el PU a través del cual se puede obtener la formalización o cualquiera de las decisiones de que trata el artículo 58; y 3) el procedimiento para la expedición de los POSPR, que posteriormente se complementa y completa con la Resolución 740 de 2017 de la ANT, que establece su reglamento operativo.

Así las cosas, en el caso de los actos administrativos que admiten o recha- zan la inscripción al RESO, es posible reconocer en la formación de estas decisiones, algunos visos de la tipología de "administración imperativa", con una sujeción a la legalidad vertical, que se corresponde con los procedimientos de primera generación a los que se ha hecho referencia, siguiendo a Barnes (2011).

Ahora bien, la incidencia del principio de participación se vislumbra, ante todo, en el ámbito del PU. En este se puede identificar un tránsito hacia la segunda y tercera generación de procedimientos, que da cuenta de la tendencia de la Administración hacia la formulación de planes y programas con incidencia territorial. Se trata de una Administración vinculada a la legalidad de manera estratégica, con mayores campos de discrecionalidad. Los caracteres del procedimiento administrativo de tercera generación, esto es, de aquel que propende por estrategias de gobernanza, se evidencia en los procesos de formulación, implementación y mantenimiento de los POSPR, en los que se hace un fuerte llamado a la participación social y comunitaria.

La operatividad de estos planes deja, sin embargo, dudas con respecto a las alternativas para que la participación sea efectiva en la toma de decisiones, por lo que en este caso solo se puede afirmar el reconocimiento de algunos rasgos de los procedimientos de tercera generación. No obstante, el carácter especial de estos procedimientos permite que los vacíos en torno a las condiciones para hacer efectiva la participación se complementen 
a partir de las reglas del procedimiento administrativo general previsto en la Ley 1437 de 2011.

Los ejemplos propuestos pretenden mostrar que las circunstancias sociales y políticas que corresponden al momento histórico de implementación del posacuerdo, han permeado las finalidades de la administración pública, las manifestaciones de la función administrativa del Estado y en particular, el acto administrativo y la teoría que subyace en el caso colombiano, como consecuencia de las demandas de participación ciudadana, en tanto alternativa para transitar hacia el objetivo de una paz estable y duradera. La participación ciudadana supone, ineludiblemente, revisar desde el punto de vista teórico, atributos tan marcados de los actos administrativos como su carácter unilateral, propiedad que desde la construcción dogmática del derecho administrativo ha estado estrechamente relacionada con las prerrogativas del poder público.

El principio de participación cumple así, según Schmidt-Assmann (2014), una función que se manifiesta desde una perspectiva dogmática y una dimensión configuradora del sistema. La perspectiva dogmática se registra en la influencia de principios constitucionales como el de participación, en el procedimiento administrativo. Por su parte, la función configuradora del sistema impacta la teoría del derecho administrativo, en este caso, del acto administrativo, puesto que convoca a revisar las instituciones características de esta disciplina, desde referentes como los derechos fundamentales y la legitimación democrática de la Administración.

\section{CONCLUSIONES}

Las condiciones que dieron lugar a la inserción de la teoría del acto adminis trativo en Colombia en el proceso que va desde finales del siglo XIX y mediados del XX, están determinadas por el interés conservador de consolidar la estabilidad política y administrativa bajo un perfil de administración jerárquica y centralizada, cuyas decisiones son el resultado de un procedimiento vertical y de una fuerte idea del poder público.

El Estado social de derecho, definido en la Constitución de 1991, su carácter democrático, participativo y pluralista, se afianza a instancias del posacuerdo, bajo la idea de procedimientos que exigen la formación de los actos administrativos con amplia audiencia y participación de los grupos sociales y económicos interesados en la decisión.

Se ha activado un dispositivo dinamizador de las prácticas administrativas colombianas. Este dispositivo es el Acuerdo de Paz, el cual, a partir de la transición que intenta promover de manera general, puede tener también la capacidad de repercutir en la manera en la que la administración pública se relaciona ordinariamente con los ciudadanos a través del procedimiento administrativo. Cabe tener en cuenta para esto, que la magnitud e importancia de los temas que abarca el Acuerdo no es 
ni mucho menos coyuntural en un país como Colombia.

A pesar de que el CPACA tiene previsiones que hacen posible la orientación de los asuntos del Estado por medios alternativos a los tradicionales, lo cierto es que el riesgo del comportamiento inercial hacia estos exige impulsos, como el que le da el Acuerdo, que le muestren a la administración un modo diferente de proceder, sobre todo para reforzar la idea del potencial que tiene el hecho de que los ciudadanos se sientan convocados para definir las decisiones públicas y, consecuencialmente, también se sientan parte de su efectividad (Marín Hernández, 2016).

La adaptación de una forma de ser administrativa a la fórmula lapidaria del Estado social de derecho, tiene en el Acuerdo de Paz uno de los retos más interesantes de la historia constitucional colombiana, al menos de la que se ha escrito desde la expedición de la Carta Política de 1991. Mostrará por lo menos, un camino posible para resolver el eterno problema entre el ejercicio de la autoridad y la garantía de los derechos, y será el indicador para evaluar hasta dónde la administración pública colombiana tiene la disposición para adecuar su actividad a la principialística constitucional, o hasta dónde el peso de la tradición autoritaria continúa permeando las instituciones administrativas, muy a pesar de los arreglos normativos que se introduzcan, no importa en qué instancia del sistema jurídico se dispongan.

\section{REFERENCIAS}

Agencia Nacional de Tierras (2017). Resolución 740. Por la cual se expide el reglamento operativo de los planes de ordenamiento social de la propiedad, el proceso único de ordenamiento social de la propiedad y se dictan otras disposiciones.

Agencia de Renovación del Territorio (2018). Respuesta a solicitud de información.

Alexy, R (2008). Teoría de los derechos fundamentales ( $2^{\mathrm{a}}$ ed.). Madrid, Centro de estudios políticos y constitucionales.

Asamblea Nacional Constituyente (ANC) (1991). Constitución Política de Colombia. Bogotá: República de Colombia. Recuperado de http://www.constitucioncolombia.com/ indice.php

Barnes, J (2011). Tres generaciones de procedimiento administrativo. En P. Aberastury y H. Blanke. (Eds.), Tendencias Actuales del Procedimiento Administrativo en Latinoamérica y Europa. Presentación de la traducción de la Ley alemana de procedimiento administrativo (pp. 120-164). Buenos Aires: Fundación Konrad Adenauer, Eudeba.

Blanke, H (2011). La función del procedimiento administrativo para el cumplimiento del mandato de ejecución, protección y concretización del derecho administrativo. Márgenes de discrecionalidad y de apreciación. En P. Aberastury, y H. Blanke. (Eds.), Tendencias Actuales del Procedimiento Administrativo en Latinoamérica y Europa. Presentación de la traducción de la Ley alemana de procedimiento administrativo (pp. 21-51). Buenos Aires: Fundación Konrad Adenauer, Eudeba.

Cassese, S. (2014). Derecho Administrativo: Historia y Futuro. España: Global Law Press, Editorial Derecho Global. Recuperado de: https://play. google.com/books/reader?id=2WKTBQAAQ BAJGhl=esEpg=GBS.PPl.w.3.0.0. 
Congreso de la República (2011). Ley 1437 de 2011. Por la cual se expide el Código de Procedimiento Administrativo y de lo Contencioso Administrativo. Diario Oficial (47.956). Recuperado de http://www.funcionpublica.gov. co/eva/gestornormativo/norma.php?i=41249

Congreso de la República (2017a). Proyecto de Ley No. 13 de 2017. Senado 022 de 2017 Cámara. "Por medio de la cual se desarrolla el tratamiento penal diferenciado para pequeños cultivadores y cultivadoras, de acuerdo con las disposiciones del artículo 5 transitorio del Acto Legislativo 01 de 2017 y el numeral 4.1.3.4 del Acuerdo Final para la terminación del conflicto y la construcción de una paz estable y duradera".

Congreso de la República (2017b). Proyecto de Ley No. 018 de 2017 Cámara No. 009/2017 Senado. "Por la cual se habilita la adjudicación o el otorgamiento de uso de baldíos en reservas forestales protectoras - productoras y de reserva forestal de la Ley $2^{\text {a }}$ de 1959, sin sustracción y se dictan otras disposiciones".

Congreso de la República (2017c). Proyecto de Ley No. 019 de 2017 Cámara- No. 010 de 2017 Senado "Por la cual se regula el sistema nacional catastral multipropósito"; el Proyecto de ley orgánica No. 020 de 2017 Cámara - No. 011 de 2017 Senado "Por la cual se modifica la ley 152 de 1994".

Diez, M (1961). El acto administrativo. Buenos Aires: Tipografía Editora Argentina S.A.

Duguit, L (1975). Las transformaciones del Derecho. Buenos Aires: Editorial Heliasta S.R.L.

Forsthoff, E. (1958) Tratado de derecho administrativo. Madrid: Instituto de Estudios Políticos.

García Oviedo, C. (1962). Derecho administrativo (8º ed.). Madrid: Imprenta Provincial.

Garrido, F. (2005). Tratado de Derecho Administrativo (14º ed.). Madrid: Tecnos.
Giannini, M. S. (1991). Derecho Administrativo (Vol. 1). Madrid: Ministerio para las Administraciones Públicas.

Gobierno Nacional y FARC-EP (2016). Acuerdo final para la terminación del conflicto y la construcción de una paz estable y duradera. Recuperado de http://www.altocomisionadoparalapaz.gov. co/procesos-y-conversaciones/Paginas/ Texto-completo-del-Acuerdo-Final-para-laTerminacion-del-conflicto.aspx

Gordillo, A. (1964). Tratado de Derecho Administrativo. Buenos Aires: Fundación de Derecho Administrativo.

Henao, J. (2014). Estado Social y Derecho Administrativo. En A. Montaña y A. Ospina. (Eds.), La constitucionalización del Derecho Administrativo. XV Jornadas Internacionales de Derecho Administrativo (pp. 145-201). Bogotá: Universidad Externado de Colombia.

Instituto Kroc de Estudios Internacionales para la Paz (2017). Informe sobre el estado efectivo de implementación del Acuerdo de Paz en Colombia. Notre Dame: Universidad de Notre Dame. Recuperado de: http://static.iris.net.co/semana/upload/documents/informe-kroc.pdf

López, D. (2007). El sueño weberiano: claves para una comprensión constitucional de la estructura administrativa del Estado Colombiano. Revista de Derecho Público, 1. Recuperado de https://derechopublico. uniandes.edu.co/components/com_revista/ archivos/derechopub/publ28.pdf

Malagón, M. (2007). Vivir en policía. Una contralectura a los orígenes del derecho administrativo colombiano. Bogotá: Universidad Externado de Colombia.

Malagón, M. (2012). Los modelos de control administrativo en Colombia. Bogotá: Universidad de los Andes.

Marín, H. (2016). El procedimiento administrativo como herramienta para la paz. En A. Montaña 
y A. Ospina. (Eds.), La constitucionalización del Derecho Administrativo (pp. 395-438). Bogotá: Universidad Externado de Colombia.

Ministerio de Agricultura y Desarrollo Rural (2017). Resolución 464 de 2017. Por la cual se adoptan los lineamientos estratégicos de política pública para la Agricultura Campesina, Familiar y Comunitaria y se dictan otras disposiciones. Diario Oficial (50.505). Recuperado de https://www.minagricultura.gov.co/Normatividad/Resoluciones/ Resoluci\%C3\%B3n\%20No\%20000464\%20 de\%202017.pdf

Montaña, A. (2010). Fundamentos de derecho administrativo. Bogotá: Universidad Externado de Colombia.

Montaña, A. (2015). El Estado de derecho y la idea constitucional de un derecho administrativo. En A. Montaña y A. Ospina, (Eds.), La constitucionalización del derecho administrativo (pp. 63-77). Bogotá: Universidad Externado de Colombia.

Ospina, A. (2016). El derecho administrativo como constructor de paz. En A. Montaña y A. Ospina. (Eds.), La constitucionalización del derecho administrativo (pp. 11-17). Bogotá: Universidad Externado de Colombia.

Parejo Alfonso, L. (2000). El Estado social administrativo: algunas reflexiones sobre la "crisis" de las prestaciones y los servicios públicos. Revista de Administración Pública, (153), 217-249.

Peña, D. (2006, junio). El trasegar del acto administrativo en Colombia: entre el retrato y la conveniencia. Revista de Derecho Público 1, 3-17. Recuperado de https://derechopublico. uniandes.edu.co/components/com _ revista/ archivos/derechopub/pub127.pdf

Peña, D. (2008). La construcción del derecho administrativo colombiano. Bogotá: Ediciones Uniandes.
Pineda Salazar, H. (1991, abril 19). Estamos aquí por el fracaso de la Constitución de 1886. Gaceta Constitucional (50a), 7-9. Recuperado de http://babel.banrepcultural.org/cdm/ compoundobject/collection/p17054coll26/ id/3850/show/3788/rec/11

Presidente de la República (1984, enero 2). Decreto 01 de 1984. Por el cual se reforma el Código Contencioso Administrativo. Diario Oficial (36.439). Recuperado de http://www. sic.gov.co/sites/default/files/normatividad/ Dec01_1984.pdf

Presidente de la República (2017). Decreto 249 de 2017. Por el cual se regula la erradicación manual de cultivos ilícitos en el marco del Acuerdo Final para la Terminación del Conflicto y la Construcción de una Paz Estable y Duradera. Diario Oficial (50.147). Recuperado de http://www.funcionpublica.gov.co/eva/ gestornormativo/norma.php?i=79354

Presidente de la República (2017). Decreto 691 de 2017. Por el cual se sustituye el Fondo para la Sostenibilidad Ambiental y Desarrollo Rural Sostenible en Zonas Afectadas por el conflicto por el "Fondo Colombia en Paz" (FCP) y se reglamenta su funcionamiento. Diario Oficial (50.217). Recuperado de http:// es.presidencia.gov.co/normativa/normativa/ DECRETO\%20691\%20DEL\%2027\%20DE\%20 ABRIL\%20DE\%202017.pdf

Presidente de la República (2017). Decreto 884 de 2017. Por el cual se expiden normas tendientes a la implementación del Plan Nacional de Electrificación Rural en el marco del Acuerdo Final para la Terminación del conflicto y la construcción de una paz estable y duradera. Diario Oficial (50.245). Recuperado de http:// www.funcionpublica.gov.co/eva/gestornormativo/norma.php?i $=81837$

Presidente de la República (2017). Decreto ley 870 de 2017. Por el cual se establece el Pago por Servicios Ambientales y otros incentivos a la conservación. Diario Oficial (50.244). 
Recuperado de https://www.alcaldiabogota. gov.co/sisjur/normas/Normal.jsp?i=70319

Presidente de la República (2017). Decreto ley 882 de 2017. Por el cual se adoptan normas sobre la organización y prestación del servicio educativo estatal y el ejercicio de la profesión docente en zonas afectadas por el conflicto armado. Diario Oficial (50.245). Recuperado de http://es.presidencia.gov.co/ normativa/normativa/DECRETO\%20882\%20 DEL\%2026\%20DE\%20MAYO\%20DE\%20 2017.pdf

Presidente de la República (2017). Decreto ley 883 de 2017. Por el cual se modifica la Ley 819 de 2016 para incluir a las empresas dedicadas a la minería y a la explotación de hidrocarburos en la forma de pago de obras por impuestos. Diario Oficial (50.245). Recuperado de http:// es.presidencia.gov.co/normativa/normativa/ DECRETO\%20883\%20DEL\%2026\%20DE\%20 MAYO\%20DE\%202017.pdf

Presidente de la República (2017). Decreto ley 890 de 2017. Por el cual se dictan disposiciones para la formulación del Plan Nacional de Construcción y Mejoramiento de Vivienda Social Rural. Diario Oficial (50.247). Recuperado de http://es.presidencia.gov.co/ normativa/normativa/DECRETO\%20890\%20 DEL\%2028\%20DE\%20MAYO\%20DE\%20 2017.pdf

Presidente de la República (2017). Decreto ley 896 de 2017. Por el cual se crea el Programa Nacional Integral de sustitución de cultivos de uso ilícito. Diario Oficial (50.248). Recuperado de http://es.presidencia.gov.co/normativa/ normativa/DECRETO\%20896\%20DEL\%20 29\%20DE\%20MAYO\%20DE\%202017.pdf
Presidente de la República (2017). Decreto ley 902 de 2017. Por el cual se adoptan medidas para facilitar la implementación de la Reforma Rural Integral contemplada en el Acuerdo Final en materia de tierras, específicamente el procedimiento para el acceso y formalización y el Fondo de Tierras. Diario Oficial (50.248). Recuperado de http:// es.presidencia.gov.co/normativa/normativa/ DECRETO\%20902\%20DEL\%2029\%20DE\%20 MAYO\%20DE\%202017.pdf

Rodríguez de Santiago, J. M. (2007). La administración del Estado social. Barcelona: Marcial Pons.

Santofimio, J (2007). Tratado de derecho administrativo: acto administrativo, procedimiento, eficacia y validez. Bogotá: Universidad Externado de Colombia. Centro de Investigación en Filosofía y Derecho.

Sayagués, E (1965). Tratado de derecho administrativo. Montevideo: Fundación de Cultura Universitaria.

Schmidt-Assmann, E. (2003). La teoría general del derecho administrativo como sistema. Objeto y fundamentos. Barcelona: Instituto Nacional de Administración Pública, Marcial Pons, Ediciones Jurídicas y Sociales, S.A.

Schmidt-Assmann, E. (2014). El concepto de la constitucionalización del derecho administrativo. En A. Montaña y A, Ospina (Eds.), La constitucionalización del derecho administrativo (pp. 21-38) Bogotá: Universidad Externado de Colombia.

Tascón, T. (1942). Derecho Contencioso Administrativo Colombiano. Comentarios al nuevo Código de la Materia. Ley 167 de 1941. Bogotá: Minerva S.A. 